\title{
Disidencia y normalización sexual en los primeros cómics de Ralf König: Schrwulcomix 1, entre la liberación gay y la emergencia de lo queer
}

\author{
Sexual Dissidence and Sexual Normalization in Ralf \\ König's First Comic Books: Schwulcomix 1 between Gay \\ Liberation and the Emergence of the Queer Movement
}

\author{
Atilio Raúl Rubino \\ (UNLP/CONICET)
}

Atilio Raúl Rubino es profesor y doctor en Letras por la Facultad de Humanidades y Ciencias de la Educación de la Universidad Nacional de La Plata (FaHCE-UNLP), Buenos Aires, Argentina. Su tesis doctoral trató sobre las representaciones de las sexualidades en distintos medios culturales durante la década de los setenta en la República Federal de Alemania. Actualmente, se desempeña como becario post-doctoral del Consejo Nacional de Investigaciones Científicas y Técnicas (CONICET), como investigador en formación del Instituto de Investigaciones en Humanidades y Ciencias Sociales (IdIHCS - UNLP/ CONICET) y como docente en la cátedra de Introducción a la literatura del Departamento de Letras (FaHCE-UNLP).

Fecha de recepción: 19 de agosto de 2018

Fecha de aceptación definitiva: 24 de noviembre de 2018 


\title{
Resumen
}

En este artículo se aborda el primer volumen compilatorio del historietista alemán más importante de las últimas décadas: Ralf König. Publicado en 1980, Schwulcomix 1 puede ser pensado justamente en la encrucijada entre dos épocas, la década de la liberación gay-lésbica y la década que significó la emergencia de lo queer. En este sentido, se analizarán en los cómics tempranos de König cuestiones como la massmediatización de la homosexualidad, su uso como espectáculo y entretenimiento, así como la representación de la homosexualidad como una enfermedad (que anticipa el uso biopolítico del VIH-SIDA).

Palabras clave: Disidencia sexual, estudios queer, historieta alemana, Ralf König, movimiento gay-lésbico

\begin{abstract}
This article deals with the first compilation of the work by the most important German strip cartoonist of the last few decades: Ralf König. Released in 1980, Schwulcomix 1 can be considered to be right in-between two eras: the gay-lesbian liberation decade and the decade that meant the emergence of the queer movement. In this sense, issues such as the massmediatization of homosexuality, its use as a show and as entertainment, as well as the representation of homosexuality as a disease (anticipating the biopolitical use of HIV/ AIDS) shall be analyzed in König's early comic books.
\end{abstract}

Keywords: gay-lesbian movement, German comic, Ralf König, sexual dissidence, queer studies

\section{Cita bibliográfica}

Rubino, A. R. «Disidencia y normalización sexual en los primeros cómics de Ralf König: Schwulcomix 1, entre la liberación gay y la emergencia de lo queen», en CuCo, Cuadernos de cómic, n. ${ }^{\circ} 11$ (2018), pp. 7-29. 


\section{Introducción}

En este artículo me interesa abordar los cómics tempranos de uno de los historietistas más importantes de Alemania: Ralf König. Me refiero, fundamentalmente, a los cómics publicados en su primer volumen compilatorio Schwulcomix 1 de $1980 .{ }^{1}$ Como año bisagra entre la década de los setenta y la de los ochenta, me interesa pensar cómo los cómics de König publicados en 1980 dan cuenta de una incipiente normalización de lo gay y de algunas primeras críticas al movimiento gay-lésbico que luego serán características de la perspectiva queer. Es decir: se puede observar una tensión entre disidencia ${ }^{2}$ y normalización sexual. ${ }^{3}$

Con la rebelión de Stonewall en 1969, se constituyen las identidades gay y lesbiana como fuerzas políticas. ${ }^{4} \mathrm{El}$ mismo año, en la República Federal de Alemania, se lleva a cabo la derogación de la ley que prohibía las relaciones sexuales entre hombres (el parágrafo $175 \mathrm{del}$ código penal). Claro que esta despenalización es solo parcial, ya que estas prácticas dejaban de ser ilegales para personas mayores de dieciocho años, mientras que las relaciones heterosexuales eran legales desde los catorce años de edad. De cualquier forma, esto posibilitó las primeras organizaciones militantes alemanas en torno a lo que se conoció como la Schwulenberwegung (el movimiento de liberación gay-lésbica). La palabra Schwul en Alemania es el término con el que se autoproclaman las identidades disidentes a partir de los años setenta. Así como queer, palabra con la que convive después de los noventa, se trata de un

${ }^{1}$ Publicado en 1980 por Rosa Winkel Verlag, Schwulcomix 1 reunía algunos cómics cortos anteriores de König, en donde se puede observar todavía una vacilación en el estilo tanto visual del dibujo como en cuanto al tipo de humor respecto al que luego lo haría característico. En este artículo, cito los respectivos cómics de Schwulcomix 1 por el primer número de la reedición de las obras tempranas de 2014: KöNIG, R. Der junge König. 1. Die frühen Comix (1980-1984). Hamburg, Männerschwarm Verlag, 2014.

2 Por disidencia me refiero a aquellas manifestaciones de sexualidad que cuestionan el régimen heteronormativo y la matriz heterosexual. Hablar de sexualidades disidentes permite, así, entrar en la dinámica de los dispositivos de poder, control y producción de cuerpos sexuados que están en juego. Una discusión más detallada de este concepto se encuentra en Rubino, A. Sexualidades disidentes en la literatura y el cine de habla alemana (1969-1980) [Tesis Doctoral]. FaHCE-UNLP, 2017, pp 23-26.

3 Duggan retoma el término heteronormatividad de Warner, M. «Introduction», en Warner M. (ed.), Fear of a queer planet: queer politics and social theory. Minneapolis, University of Minnesota Press, 1993, pp. VIIXXXI, para hablar también de la existencia de una homonormatividad a la que define como «a politics that does not contest dominant heteronormative assumptions and institutions, but upholds and sustains them, while promising the possibility of a demobilized gay constituency and a privatized, depoliticized gay culture anchored in domesticity and consumption». Duggan, L. The twilight of equality? Neoliberalism, cultural politics, and the attack on democracy. Boston, Beacon Press, 2003, p. 50.

${ }^{4}$ Jagose, A. Queer theory: an introduction. New York, New York University Press, 1996, p. 30. 
insulto resignificado, que puede ser traducido como «puto». ${ }^{5}$ Córdoba García menciona la convivencia de tres posiciones durante los años setenta: la liberacionista, que fue hegemónica, el modelo de diferencia étnica y los discursos minoritarios de «crítica a la identidad y sus efectos de exclusión que marcan el punto de aparición de la política queenn. ${ }^{6} \mathrm{El}$ modelo queer surge, entre otras cosas, de esta confrontación de las disputas en los años ochenta dentro del feminismo alrededor de la pornografía y de las prácticas disidentes, como el BDSM lésbico. Con el estallido en esos mismos años de la crisis del VIH-SIDA, comienza a surgir un cuestionamiento de la identidad esencialista que termina institucionalizándose en los años noventa, como la perspectiva queer, que se combina con posturas post-estructuralistas respecto de la identidad y la sexualidad. Si bien los estudios queer implican una importante ruptura epistemológica respecto a la concepción de la sexualidad de los discursos liberacionistas de la década de los setenta, es importante tener en cuenta que esta ruptura ya se estaba gestando desde antes, fundamentalmente desde sectores como el feminismo lesbiano radical y el postestructuralismo. La ruptura epistemológica, que generalmente se ubica en los noventa en Estados Unidos, para Preciado ocurre primero en los años setenta y también en Europa, y es retomada después por el campo de los estudios queer. ${ }^{7} \mathrm{La} S c h w u-$ lenberwegung (el movimiento de liberación gay-lésbico de la República Federal de Alemania) tiene su emergencia, desarrollo y declive entre los años 1969 y $1980 .{ }^{8}$ Sin embargo, lo que una historia lineal y cronológica de la disidencia sexual marca como saltos epistémicos en distintos períodos y con núcleos espacio-geográficos de influencia, también pueden ser leídos antes de su institucionalización. Si el movimiento de liberación de los setenta surgió con un fuerte carácter disidente, hacia el final de la década comienza a normalizarse para formar parte del sistema y buscar la aceptación — generando el caldo de cultivo para la emergencia de una nueva perspectiva disidente hacia mediados de los ochenta asociada con la resignificación de la palabra queer en Estados Unidos-, mediante el análisis de un corpus de diferentes medios culturales, como la historieta, podemos observar cómo esas tensiones ya estaban presentes desde los setenta, con algunas problematizaciones y cuestionamientos que luego serán característicos de la perspectiva queer. Javier Sáez menciona la confluencia de la normalización del modelo gay norteamericano y su transnacionalización junto a la epidemia del VIH-SIDA como las crisis que posibilitaron el surgimiento de lo

${ }^{5}$ Según Jens Dobler, la palabra Schwul también era usada por lesbianas como identidad. Se trataba en ambos casos de una forma de contrarrestar la normalidad relacionada con la homosexualidad. Implicaba una autodefinición, a partir del uso de un insulto (Schimpfwort) para poner en primer plano y exagerar la estigmatización y la estereotipación, y generar dentro de la Schwulenberwegung una nueva y colectiva interpretación, generar un nosotros colectivo y, de ese modo, evitar las definiciones desde afuera. Dobler, J. «Schwule Lesben», en Pretzel, A. y Weiss, V. (eds.). Rosa Radikale. Die Schwulenberwegung der 1970er Jahre. Hamburg, Männerschwarm Verlag, 2012.

${ }^{6}$ Córdoba García, D. «Teoría queer: reflexiones sobre sexo, sexualidad e identidad. Hacia una politización de la sexualidad», en Córdoba García, D. Sáez, J. y Vidarte, F. J. (eds.). Teoría queer: políticas bolleras, maricas, trans, mestizas. Barcelona/Madrid, Egales, 2005, p. 39.

7 Preciado, P. B. «Terror anal: apuntes sobre los primeros días de la revolución sexual», en Hocquenghem, G. y Preciado, P. B. El deseo homosexual (con terror anal). Barcelona, Melusina, 2009.

${ }^{8}$ Holy, M. «Jenseits von Stonewall - Rückblicke auf die Schwulenbewegung in der BRD 1969-1980», en Pretzel, A. y Weiss, V. (eds.). Op. cit., pp. 39-79. 
queer. ${ }^{9}$ En la República Federal de Alemania, según Holy, a partir de 1977 comienza la mayor influencia transnacional de la Gay-Liberation-Bewegung norteamericana, debido a la fascinación por Stonewall y el American Way of Life. ${ }^{10}$ Esta tendencia se consolida en 1979 en el Homolulu Festival en Frankfurt, con el primer Gay Parade y la presentación de una «schwuler Gegenkultur» (contracultura $S c h w u l)^{11}$ pero cada vez comienzan a incorporarse más y más sentidos y símbolos del orgullo gay norteamericano. ${ }^{12}$ En su periodización de la Schwulenberwegung en la República Federal de Alemania, Holy denomina al período 19761979 como «Amerikanisierung». ${ }^{13}$ En este sentido, hacia los ochenta, se genera un cambio de paradigma, pues ya comienza una clara normalización Schwul con la inclusión dentro de las instituciones de políticas de líneas más integracionistas que disidentes.

\section{Ralf König, el historietista Schrul alemán}

Desde sus primeros cómics, Ralf König tematiza y combate mediante el humor los prejuicios y estereotipos de la comunidad LGBTIQ alemana. ${ }^{14}$ Plagada de referencias intermediales, su obra es de una riqueza enorme y en su trayectoria desde comienzos de los años ochenta hasta la actualidad se puede hacer un recorrido por los distintos temas propios de la comunidad disidente: sexualidad, matrimonio, VIH-SIDA, pornografía, cultura BDSM-leather, entre otros. Como comenta Saxe, «König se volvió un cronista de lo que aconteció a la sexualidad disidente en las últimas tres décadas en Alemania y marcó a una generación con sus Knollennasen». ${ }^{15} \mathrm{Si}$ bien se trata de cómics humorísticos, en estos primeros trabajos de König podemos ver algunas de las cuestiones que eran tema de debate en el seno de la comunidad Schwul y disidente. Con un claro sesgo militante y complejizador, König recorre los temas propios de la comunidad gay alemana: «La masculinidad, la gayness, el coming-out, los espacios homosociales gay, las relaciones íntimas en la comunidad gay, la política gay, la militancia gay, el amor y el sexo gay, entre otros temas, se repiten en las diferentes historias». ${ }^{16}$

Ralf König es probablemente el historietista alemán más leído. Su trayectoria comienza en la subcultura gay-Schwul alemana con los cuatro tomos de los Schwulcomix (1980-1986) y

\footnotetext{
9 SÁEz, J. «El contexto sociopolítico de surgimiento de la teoría queer. De la crisis del sida a Foucault», en Córdoba García, D. Sáez, J. y Vidarte, F. J. (eds.). Op. cit., p. 67.

10 Holy, Op. cit., p. 63.

11 Salmen, A. y Eckert, A. «Die neue Schwulenbewegung in der Bundesrepublik Deutschland zwischen 1971 und 1987. Verlauf und Themen», en Forschungsjournal Neue Soziale Berwegungen n. o 2, (1988), p. 228.

12 Holy, M. Op. cit., p. 69.

13 Ibid., p. 62.

14 SAXE, F. Representación transnacional de las sexualidades disidentes en textos culturales alemanes recientes (19872012) [Tesis doctoral], FaHCE-UNLP, 2014, p. 123. Facundo Saxe es quien probablemente ha estudiado la obra historietística de König con mayor profundidad. Sus diferentes estudios se ocupan fundamentalmente del período 1986-2012 en la producción de König.

15 Ibid., p. 129.

16 Ibid., p. 132.
} 
Machocomix (1983). Según Saxe, el acceso a un público más masivo se da a partir de 1987 con la publicación de sus primeras novelas gráficas - principalmente Der berwegte Mann, llevada al cine en 1994- en una editorial con más llegada al público masivo como Rowohlt. ${ }^{17}$ Ya en los noventa, sus novelas gráficas comienzan a ser traducidas a distintos idiomas, entre ellos al español, y a partir de su éxito, se reeditan también algunos de sus primeros cómics, como $M a-$ chocomix y los tomos 3 y 4 de Schwulcomix. ${ }^{18}$ Entre 2014 y 2016 Männerschwarm Verlag publica los tres tomos de Der junge König, que compilan las producciones de König desde 1980 hasta 1990. El tomo 1, que abarca los años 1980-1984, reedita materiales como Schwulcomix 1 $y 2$, que hasta el momento resultaban inhallables y ahora pueden ser leídos por los seguidores del historietista de habla alemana — aunque todavía no han sido traducidos al español.

La intención de este artículo, en consecuencia, es abordar la tensión disidencia/normalización sexual en algunos cómics de Schwulcomix 1 de Ralf König. En 1980, la Schrwulenberwegung alemana de principios de los setenta comenzaba ya a adoptar el modelo gay norteamericano de aceptación. Me interesa pensar esta apertura/aceptación social hipócrita respecto a la sexualidad como parte de esa tensión todavía ilegible o no institucionalizada entre disidencia y normalización dentro de las vidas no heterosexuales. Para Facundo Saxe, en los primeros números compilatorios de König, Schwulcomix 1 (1980) y Schwulcomix 2 (1983), «la representación de la vida íntima y pública de los varones homosexuales alemanes se vuelve una de las constantes de las diferentes historias». ${ }^{19}$ Detenernos justamente en 1980 significa tomar un año clave del cambio de década, entre los años setenta de la liberación y los ochenta de la emergencia de lo queer. De esta forma, los discursos disciplinadores se recrudecen anticipando la crisis del modelo gay-lésbico, que, en general, se ubica temporalmente a mediados de los ochenta, ${ }^{20}$ con la asimilación capitalista de la cultura gay. Esta normalización de la homosexualidad se evidencia en los comics de König, en donde los mass media tienen una enorme incidencia como dispositivos de subjetivación. Asimismo, en Schwulcomix 1, se pone al descubierto la hipocresía social respecto a los supuestos avances de la cultura Schwul después de la derogación parcial del parágrafo 175 en 1969 y la militancia de los setenta. Podemos ver hasta qué punto la sexualidad se ha vuelto objeto no solo de análisis y de discusión sino también de espectáculo y entretenimiento en los medios de comunicación de masas. La sexualidad se ha vuelto tan pública que es objeto de un nuevo saber y, en cuanto saber, implica también un poder y una hegemonía. Así, podemos pensar cuánto hay de homonormalización ${ }^{21}$ y de terror anal ${ }^{22}$ en estos discursos sociales sobre la sexualidad.

17 SAxe, F. «Representación cultural de la disidencia sexual en el cómic: los "hombres deseados" de Ralf König en Der bewegte Mann», en CuCo, Cuadernos de cómic n. ${ }^{\circ} 10$ (2018), p. 13. Disponible en http://cuadernosdecomic.com/docs/revista10/Representacion cultural de la disidencia sexual.pdf

18 SAXe, F. Op. cit., p. 124.

19 Ibid., p. 132.

${ }^{20}$ SÁez, J. Op. cit., p. 67.

${ }^{21}$ Duggan, L. Op. cit.

22 Preciado, P. B. Op. cit. 


\section{Visibilización en las calles y espectacularización en los mass media}

En los cómics de König, la homosexualidad llega a los medios y se convierte en un tema de debate público. Cualquiera puede opinar: se trata de una normalización que funciona como chivo expiatorio de la discriminación que se sigue practicando, de la condena social y moral que sigue operando sobre las sexualidades no heteronormativas. Esto se puede ver en el caso de «Schwul-comix heute: die kleine Geschichte von herr Wörms und herr Krüger» ${ }^{23}$ en donde se evidencia esta tensión propia de la época entre la visibilización o el silenciamiento de la identidad [FIG. 1 y 2 ].

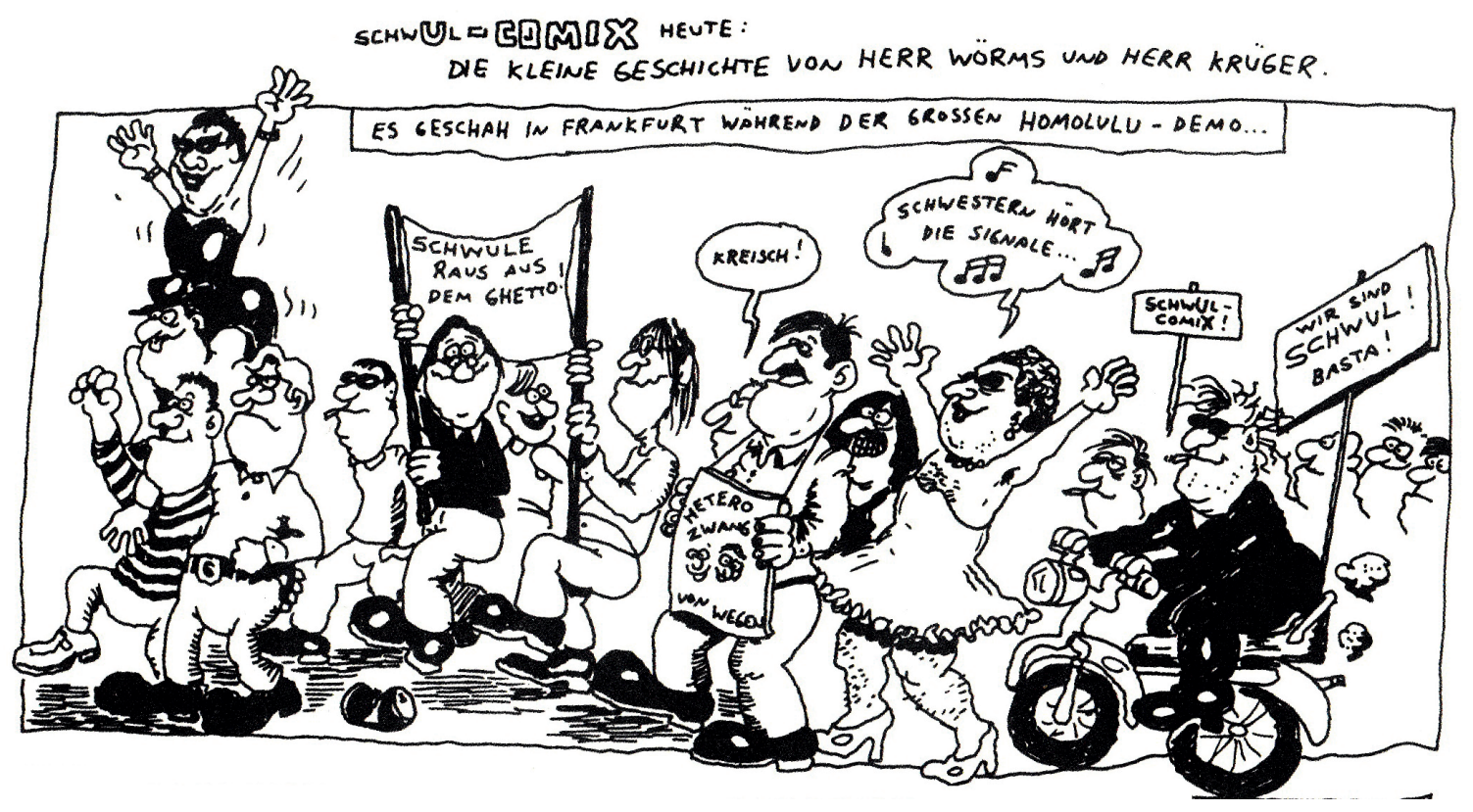

FIG. 1. KöNIG, R. «Schwul-comix heute: die kleine Geschichte von herr Wörms und herr Krüger», en Der junge König. 1. Die frühen Comix (1980-1984) [Schwulcomix 1 (1980)]. Hamburg, Männerschwarm Verlag, 2014, p. 46 (detalle).

En este cómic se representa una manifestación militante por la liberación [FIG. 1]. En ese contexto, Herr Wörms, que se identifica como Schwul, se debate entre sumarse a la manifestación - lo que siente como su deber- y los problemas que eso podría causarle a nivel laboral. Vemos cómo la gente que presencia la manifestación condena la disidencia. Incluso König ubica en un globo de diálogo, en vez de palabras de censura y condena, la cruz esvástica, para dar cuenta de hasta qué punto ese pensamiento del nacionalsocialismo sigue vigente. ${ }^{24}$ Finalmente, Herr Wörms, cuando se encuentra con su jefe Herr Krüger, decide no participar y mantener su sexualidad oculta, como forma de salvaguardar su trabajo [FIG.2].

${ }^{23}$ KöNig, R. Op. cit., p. 46.

${ }^{24}$ Es interesante mencionar, como comenta Javier Sáez, que tras la Segunda Guerra Mundial en Alemania se liberó a «judíos, gitanos y otros colectivos que habían sobrevivido al exterminio nazi, pero no a los homo- 


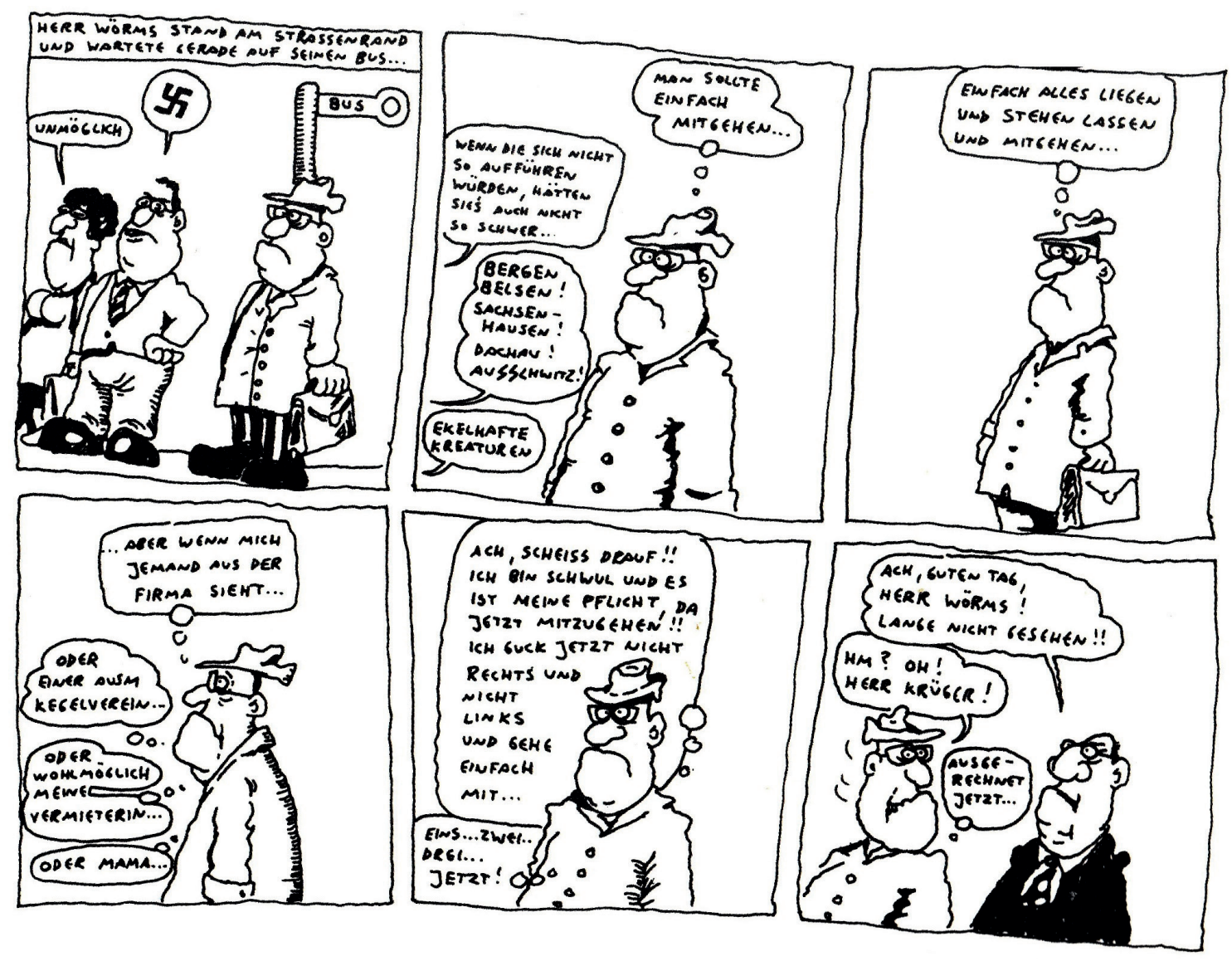

FIG. 2. KöNIG, R. «Schwul-comix heute: die kleine Geschichte von herr Wörms und herr Krüger», Schwulcomix 1 (1980), Op. cit., p. 46 (detalle).

En Schwulcomix 1 también aparecen temas como la massmediatización de la sexualidad y, particularmente, de la homosexualidad, en una época de supuesta aceptación pero en la que lo discursivo se tensiona con las prácticas. Por ejemplo, en «Was bin ich?» ${ }^{25}$ podemos ver hasta qué punto la sexualidad ha llegado a constituirse en un tema de debate público en los mass media. König presenta un programa de televisión en el que los participantes tienen que adivinar quién es una persona, en este caso un homosexual. Los participantes deben hacer preguntas sobre sus conductas y prácticas para indagar en la identidad del personaje en cuestión. De esta forma, la sexualidad se convierte en una esencia estereotipada y normalizada por los mass media. Aunque supuestamente aceptada por la sociedad, en la representación de König se vuelve un objeto de espectáculo. Y, asimismo, su definición ya no es motivo de la ciencia o de los saberes específicamente médicos o psiquiátricos, sino del sentido

sexuales. Como la homosexualidad en Alemania era ya un delito antes de la llegada del nazismo, se recuperó el código anterior y los homosexuales capturados por el terror nazi fueron mantenidos en las cárceles durante muchos años más tras la guerra» SÁEz, J. Teoría queer y psicoanálisis. Madrid, Síntesis, 2004, p. 26.

${ }^{25}$ KöNIG, R. Op. cit., pp. 17-19. 
común, que puede ser pensado a partir de la fórmula del hombre del autobús de Clapham con la que Patrick Devlin sostenía para la Inglaterra de 1965 que las leyes debían sancionar los actos considerados inmorales por el hombre común y razonable, porque estos contaminaban a toda la sociedad. ${ }^{26}$ Pero se trata de un sentido común que, obviamente, nunca es ingenuo. En el cómic en cuestión el personaje es observado y analizado, indagado, estudiado desde afuera por gente que representa el común de los espectadores de un programa de entretenimientos de la televisión. De ser definida desde el aparato médico-legal, la homosexualidad pasa a la exposición mediática convirtiéndose en algo así como un fenómeno de circo, un nuevo saber-poder [FIG.3].
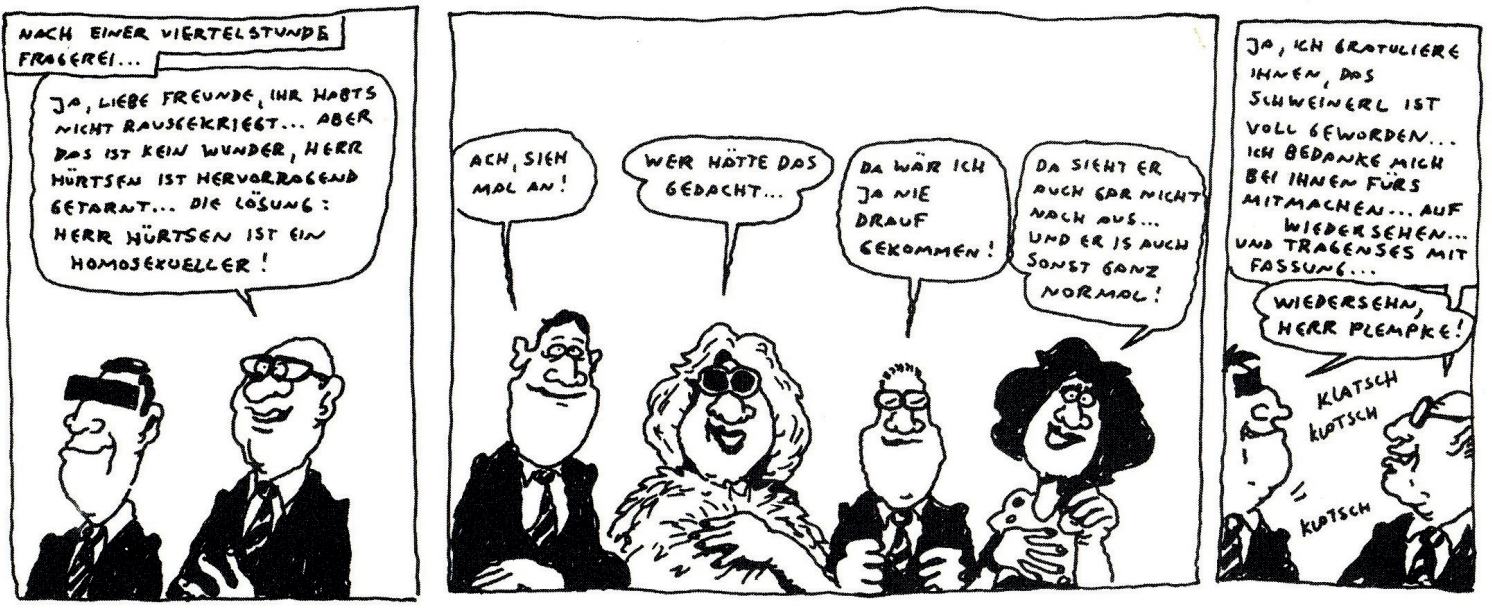

FIG. 3. KöNIG, R. «Was bin ich?», en Der junge König. 1. Diefrühen Comix (1980-1984) [Schwulcomix 1 (1980)]. Hamburg, Männerschwarm Verlag, 2014, p. 18 (detalle).

Después de intentos fallidos por parte de los participantes por adivinar la identidad de Herr Hürtsen, el presentador da la respuesta: «Herr Hürtsen ist ein Homosexueller!» [iEl señor Hürtsen es un homosexual!], ante lo que los participantes reaccionan con sorpresa: «Ach, sieh mal an!» [¡̈Ah, mirá vos!] / «Wer hätte das gedacht...» [Quién lo hubiera pensado...] / «Da wär ich nie drauf gekommen!» [No me lo hubiera imaginado] / «Da sieht er auch gar nicht nach aus und er is auch sonst ganz normal!» [¡No lo parece para nada, es tan normal!]. ${ }^{27}$ La homosexualidad no solo se ha convertido en una esencia, sino en aquello que define a una persona por completo - mediante la permanencia del «dispositivo de la sexualidad» $-{ }^{28} \mathrm{y}$, como tal, es puesta en los medios de comunicación, es una rareza, un espectácu-

${ }^{26}$ Respecto a las discusiones sobre homosexualidad y derecho, Devlin consideraba que las leyes debían resguardar la moralidad de la sociedad y esta aparecía representada en el hombre razonable, el hombre común y anónimo que viaja junto a otras personas en el autobús de Clapham. Devlin, P. The enforcement of morals. London, Oxford University Press, 1965.

27 König, R. Op. cit., p. 18.

28 Según Foucault, hacia la segunda mitad del siglo xIx con la instauración del «dispositivo de la sexualidad» la homosexualidad dejó de ser una práctica identificada como sodomía en el antiguo derecho civil y 
lo de circo para ser mirado y contemplado, un divertimento. De esta forma, el común de los espectadores, así como expresa su sorpresa, también lo hace con su desaprobación, su asco, su espanto, su mirada discriminadora: «Das is ein Schwuler!» [i Es un puto!] / «Ne'Tunte!!» [iUna marica!] / «Ein Lau-warmer!» [iUn tibio!] / «Einer vom andern Ufer!» [iUno de la otra orilla!]. ${ }^{29}$

\section{Terror anal y cisheteromasculinidad}

En este sentido, también es interesante el cómic «Selbsterfahrung». ${ }^{30}$ En él, dos parejas heterosexuales - Bern y Sonya, Axel e Inge-, que se suponen abiertas y progresistas — «ehr progressiv. Aufgeschlossen»— se juntan todos los viernes a discutir sobre sexualidad a partir de la lectura de libros especializados. Pero la indagación es tanto en la teoría como en la práctica — «versuchen sie sich neben der Theorie auch mit der Praxis»—. En este caso, están comentando un capítulo del libro Erkenne deine Sexualität, que presenta una visión psicologizante de la sexualidad, tomando las teorías de Freud, particularmente la idea de que el niño es potencialmente bisexual y que en el crecimiento va aprendiendo a definir su objeto de deseo sexual. En el crecimiento está la explicación de por qué ciertas personas tienen un comportamiento homosexual. Sin embargo, Alex y Bern están un poco incómodos y prefieren pasar a la discusión de otro capítulo porque consideran que no tienen ningún problema con los homosexuales, pero en ellos no hay ningún deseo homosexual reprimido. Inge considera que esa reacción es «Typischer fall von Angst vorm Erkennen der eigenen latenten Homosexualität» [UUn caso típico de miedo a conocer la propia homosexualidad latente»], lo que podríamos denominar, con Paul B. Preciado, como terror anal. ${ }^{31}$ Sonya e Inge, entonces, los retan a pasar a la parte práctica de la indagación, instándolos a tener sexo entre ellos. Al principio se niegan e intentan evitarlo. Luego aceptan con desgana, solo para demostrarles a ellas que no hay ninguna homosexualidad reprimida, algo que sí aceptaban en la teoría pero no si se trata de ellos, no si pone en riesgo su propia heterosexualidad. Se van al cuarto y en primer lugar intentan escapar a la prueba. Una viñeta los

canónico, para convertirse en una especie, en una «naturaleza singular»: «El homosexual del siglo xIx ha llegado a ser un personaje [...]. Nada de lo que él es in toto escapa a su sexualidad. Está presente en todo su ser: subyacente en todas sus conductas puesto que constituye su principio insidioso e indefinidamente activo; inscrita sin pudor en su rostro y su cuerpo porque consiste en un secreto que siempre se traiciona». Foucault, M. Historia de la sexualidad. 1. La voluntad de saber. Madrid, Siglo xxi, 2007, p. 56.

${ }^{29}$ KöNig, R. Op. cit., p. 19.

${ }^{30}$ Ibid., pp. 23-27.

31 Preciado utiliza el concepto de «terror anal» en dos sentidos. Uno positivo asociado al terrorismo o la rebelión y las prácticas disidentes que tienen como centro el ano. Y otro, el que aquí utilizo, tiene un sentido negativo vinculado al miedo, al horror y al pánico cisheteromasculino a todo lo anal. Preciado invierte la idea de castración freudiana, la tuerce, para considerar que esta pone al falo en el centro de lo humano. Reubicando al ano en el lugar central, Preciado convierte a la heteromasculinidad en una castración, en una falta: «Puesto a disposición de los poderes públicos, el ano fue cosido, cerrado, sellado. Así nació el cuerpo privado [...]. Así nacieron los hombres heterosexuales a finales del siglo xix: son cuerpos castrados de ano. Aunque se presenten como jefes y vencedores son, en realidad, cuerpos heridos, maltratados» Preciado, P. B. Op. cit., p. 136. 
muestra sentados en la cama y marca entre ellos una línea que indica «Sicherheitsabstand» (distancia de seguridad) [FIG. 4].
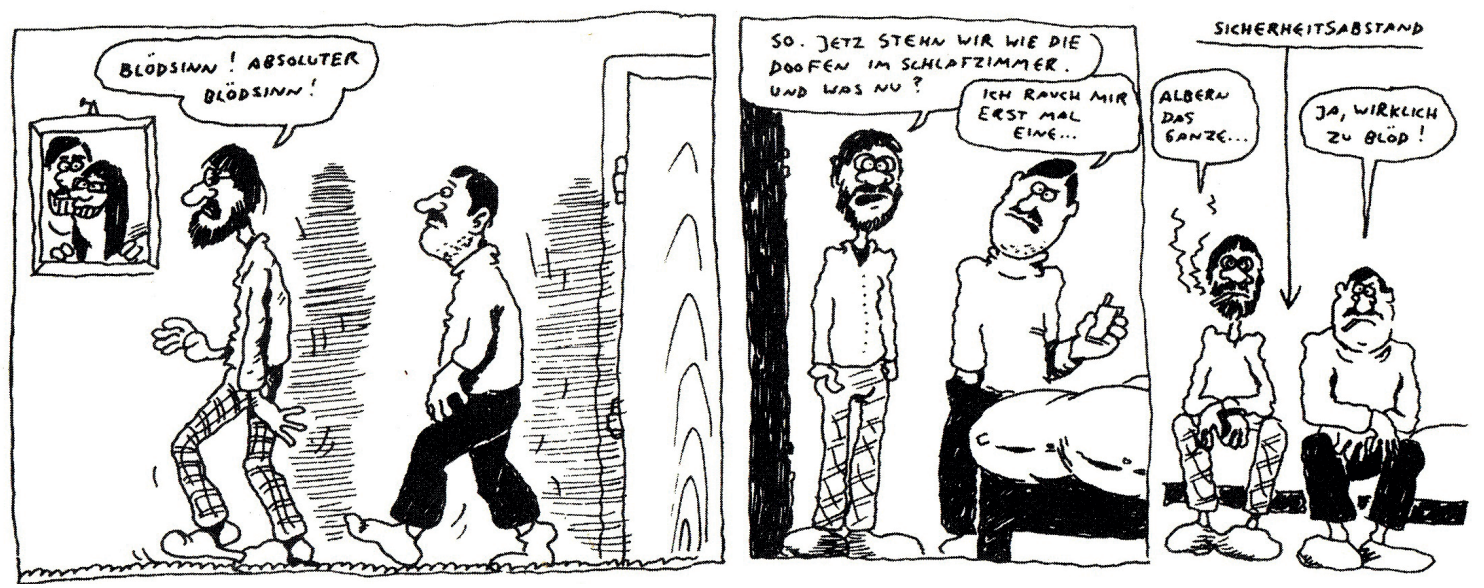

FIG.4.KöNIG, R. «Selbsterfahrung», en Derjunge König. 1. Diefrühen Comix (1980-1984) [Schwulcomix 1 (1980)]. Hamburg, Männerschwarm Verlag, 2014, p. 25 (detalle).

La clave, el código, es atravesar la prueba sin sentir nada, de modo que su heterosexualidad quede garantizada. Asimismo, lo que se supone que es una experimentación no se trata más que de comprobar lo que ya se sabe, la verdad de la heterosexualidad que ya se tiene y a partir de saberes sobre la homosexualidad, de verdades construidas al respecto: «Hmm... wie machen die Schwulen das denn? Ich kenn mich da nich so aus...» [ «Hmm... ¿cómo hacen esto los gays? No me conozco mucho...»], pregunta Alex. Bern menciona el sexo anal como una de las prácticas homosexuales habituales — «Sie ficken sich beispielsweise in der Arsch!»—, pero la respuesta de Alex es tajantemente negativa — «Nein! Kommt nicht in Frage! Nie!»- No se trata de una experimentación que cree placeres nuevos, sino de saberes acerca de la sexualidad desde el sentido común.

Alex decide entonces probar su hipótesis de que ellos no tienen homosexualidad reprimida practicándole una fellatio a Bern, pero le aclara que para él no tiene placer alguno hacer eso — «Aber denk nur nicht, es würde mir Spass machen!!»-, que lo va a hacer sin que le resulte erótico, para que no piense que es Schwul — «Nee... also, so wie er das macht... isses ja absolut unerotisch. Da tut sich nix... is auch ganz gut so, nachher denkt er noch, ich wär Schwul...»-. Pero, después de pensar en mujeres, Bern tiene una erección, mientras Alex le está practicando sexo oral. Alex en principio se enoja, pensando que es algo que Bern sí está disfrutando, pero luego, cuando le dice que pensaba en una figura femenina, se ríe aliviado [FIG. 5]. La sexualidad heteronormativa no se ve agrietada a pesar de las prácticas experimentadas con placer. Cuando Bern le cuenta lo sucedido a su mujer, le dice «es war absolut blödsinnig! Völlig unerotisch!» « «ue algo completamente tonto, para nada erótico en absoluto»], pero luego aparece una duda, inmediatamente negada: «obwohl... na, ich mein.. dir kann ichs ja sagen... so ganz ohne wars nun doch nicht..» [Aunque... bueno, 
quiero decir... no se puede ahora... decirte...]. La aceptación de la homosexualidad se da solo en términos discursivos, en la teoría. Es un alivio que, en la práctica, no hayan sentido placer, porque eso implicaría perder sus posiciones de masculinidad normativa. Aunque, claramente, ya ese era el código de antemano, antes de praticarle sexo oral ya estaba claro que sería algo de lo que no sacaría placer alguno.
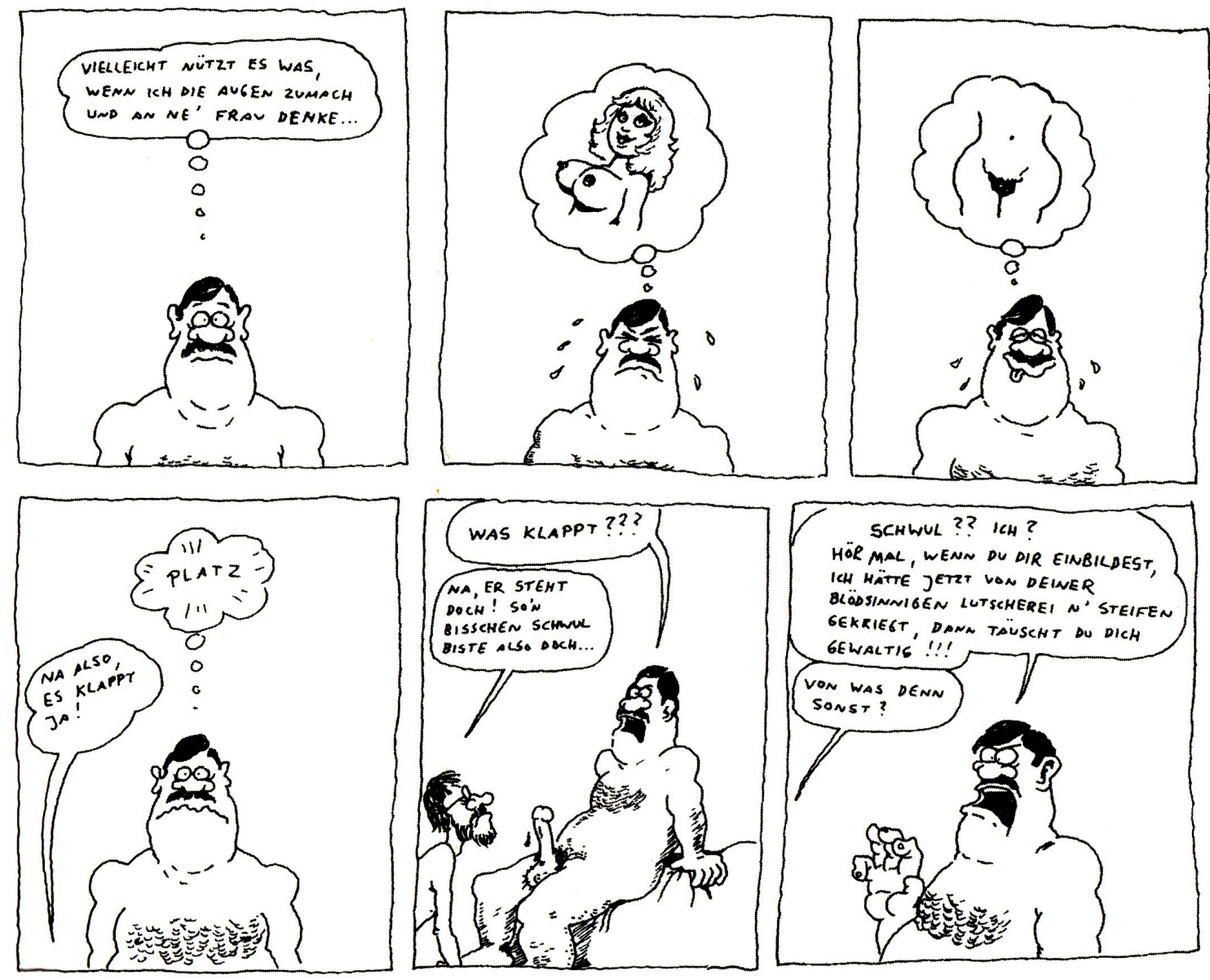

FIG.5.KöNIG, R. «Selbsterfahrung», en Derjunge König. 1. Die frühen Comix (1980-1984) [Schwulcomix 1 (1980)]. Hamburg, Männerschwarm Verlag, 2014, p. 27 (detalle).

\section{Aceptación hipócrita y homonorma}

Respecto a la ruptura con los estereotipos de belleza gay, podemos mencionar también un cómic de Schwulcomix 1 de König: «Krisen». ${ }^{32}$ En él, una pareja de homosexuales se están besando en la playa y son motivo de miradas y opiniones del resto de la gente, algunas más

32 König, R. Op. cit., p. 28-29. 
homofóbicas, que simplemente aparecen con una cruz esvástica en el globo de pensamiento, pero a otras, supuestamente más consideradas, les parece repugnante la exhibición, y aclaran que aceptan la homosexualidad porque han visto la película Die Konsequen $z^{33}$ porque en ella los protagonistas eran jóvenes y bellos:

\begin{abstract}
Also, in diesem Film damals im Fernsehen, "Die Konsequenz" oder so, mit diesem netten Jungen, da war das ja ganz schön... aber das hier... ich weiss ja nicht... [«Pero en esa película en el cine, "Die Konsequenz" o algo así, con esos jóvenes tan lindos, eso estaba bien..., pero esto aquí... no me parece...»].
\end{abstract}

En cambio, los personajes que dibuja König en la playa besándose se apartan de los estereotipos de belleza masculina gay, por eso generan algunos comentarios y reacciones. Así, un matrimonio lo considera un escándalo — «Ungeheuerlich»- o algo que no se debe mirar — «as muss man sich mal angucken...»-, a una mujer tomando sol le parece cómico — «... Sieht ja zu komisch aus...»-, otra se ríe -Kicher-. También es interesante la reacción de los niños, que parece a primera vista un poco menos prejuiciosa. Así, por ejemplo, en el globo de diálogo de uno de ellos se ve un signo de pregunta mientras la madre le tapa los ojos para que no vea. U otro niño que le dice a la madre: «Mama, guck mal, da sind zwei Männer, die sich küssen! [«iMamá, mirá, ahí hay dos hombres besándose!»] y ella le responde horrorizada «Wo? Wo?» [«¿Dónde? ¿Dónde?»]. ${ }^{34}$

Es interesante cómo en la representación de una situación cotidiana que plantea König, la supuesta aceptación de la disidencia, en realidad está sometida a la opinión desde el sentido común. Claro que ningún sentido común surge desde la ingenuidad, sino que forma parte de la producción capitalista de vidas posibles y vidas al margen, factibles del abandono. Asimismo, en otro cómic de König, «Old Heinz Comix», ${ }^{35}$ por ejemplo, un alter Schwul, un homosexual viejo, intenta tener sexo casual con un joven en un bar gay, pero obviamente esta relación es imposible y Old Heinz solo consigue rechazo y burla. Aquí aparece la personificación de dos botellas de licor que lo persiguen a Heinz como su única compañía. La edad también resulta así un parámetro biopolítico de las vidas aceptables y las que no importan, las que pueden ser abandonadas a la soledad o, como en este caso, a la única compañía del alcoholismo.

33 Die Konsequenz (1977), de Wolfgang Petersen, basada en la novela homónima de Alexander Ziegler de 1975 es la película alemana más característica del cine post-Stonewall con un mensaje aleccionador sobre la tolerancia. Como en otras películas del momento, narra el conflicto entre una sociedad intolerante y el derecho de personas del mismo sexo a amarse con la consecuencia trágica del suicidio. Mira, A. Miradas insumisas. Gays y lesbianas en el cine. Madrid, Egales, 2008, p. 85. Según Mira, «la película ilustraba así la innecesaria opresión a la que estaban sometidos los homosexuales y presentaba a dos protagonistas "normales" que no caían en los estereotipos tradicionales para reforzar este mensaje sobre el derecho a amar» Ibid., p. 376. De esta forma, es un hito importante para el cine disidente alemán pero se puede pensar también como una película aleccionadora sobre los peligros de llevar adelante una vida homosexual. Asimismo, Saxe comenta que se trata de una referencia usual en König. Por ejemplo, en la historieta «Liebe ohne Zukunft», incluida en Schwulcomix 3 (1984) se menciona a Die Konsequenz para realizar «una confrontación directa con las representaciones masivas de la homosexualidad en historias trágicas y dramáticas». SAXE, F. (2014) Op. cit., p. 132.

34 KöNIG, R. Op. cit., p. 28-29.

35 Ibid., p. 39. 


\section{Homosexualidad y enfermedad}

Me interesa detenerme ahora en un cómic de la misma época que los compilados en Schwulcomix 1, me refiero a «Der liebe Onkel», publicado en Das sensationelle Comicbook (1981). ${ }^{36}$ Antes de comentar el cómic en cuestión, es importante resaltar que el tema de las relaciones intergeneracionales era muy importante en esa época. Sebastian Haunss analiza el periódico Schwul Rosa Flieder ${ }^{37}$ entre 1979 y 1989 y encuentra que los dos temas principales en el seno de la comunidad Schwul alemana de esa época eran, por un lado, el VIH-SIDA y, por otro, los alcances de la pedofilia. La discusión pivoteaba, sobre todo, alrededor del parágrafo 175 y las diferencias que establecía entre la heterosexualidad y la homosexualidad, es decir, cómo esta última constituía un mayor peligro para la juventud. ${ }^{38} \mathrm{E}$ tema, sin embargo, cae en el silencio después de la aparición del VIH-SIDA. ${ }^{39}$

La pedofilia sigue siendo hoy en día un tema muy controvertido y silenciado incluso dentro de los estudios queer. Lo que es interesante pensar para los años setenta y ochenta es que la novedosa aceptación y despenalización de la homosexualidad traían aparejadas también el hecho de convertirla en un nuevo peligro. La visibilidad homosexual implicaba la posibilidad de contagio y, por eso, era necesario mantenerla alejada de la juventud: «El niño aparece aquí como un artefacto biopolíticamente construido que permite la producción y normalización del adulto». ${ }^{40}$ Preciado menciona, para el caso de Francia, que en 1973 la reviste Recherches publicó un número, que luego fue prohibido, en donde se abordaba el tema, pero no se trataba de

un movimiento de adultos que buscan «proteger» a los menores de los peligros de la sexualidad o de «iniciarlos» al placer, sino [de] un movimiento de menores que buscan redefinir los límites de su cuerpo, hablar de su propia sexualidad, tomar decisiones acerca del placer y de los modos de producirlo y regularlo. ${ }^{41}$

Incluso cita la propia revista, en donde los que toman la voz son los jóvenes que se autodefinen como «movimiento de liberación [que] es también un movimiento de menores contra los pederastas adultos». ${ }^{42}$ Asimismo, en una entrevista de 1978, Michel Foucault se refiere a que las leyes ya no castigan una infracción sino que protegen a ciertos sectores de la pobla-

${ }^{36}$ KöNIG, R. Op. cit., p. 154.

37 Rosa Flieder fue «die wichtigste nicht-kommerzielle schwule Bewegungszeitung» [«el más importante periódico no comercial del movimiento Schwul»] de Núremberg, en la que entre 1979 y 1989 salen 57 artículos escritos por activistas sobre temas específicos sobre la comunidad. Haunss, S. "Von der sexuellen Befreiung zur Normalität. Das Ende der Zweiten deutschen Schwulenbewegung», en Pretzel, A.y Weiss, V. (eds). Op. cit., p. 203.

38 Ibid., p. 204.

39 Ibid., p. 207.

40 Preciado, P. B. Op. cit., p. 165.

${ }^{41}$ Ibid., p. 170.

42 Idem. 
ción a los que considera "particularmente frágiles» ${ }^{43}$ y habla de todo un saber psiquiátrico y psicológico que considera a la sexualidad como un peligro:

\begin{abstract}
Y la sexualidad ya no será una conducta con ciertas prohibiciones precisas, va a convertirse en una suerte de peligro que merodea, una suerte de fantasma omnipresente, un fantasma que va a jugarse entre hombres y mujeres, entre niños y adultos y eventualmente entre los propios adultos. La sexualidad va a convertirse en esa amenaza en todas las relaciones sociales, todas las relaciones de edad, todas las relaciones de individuos [...]. Habrá con ello todo un nuevo régimen de control de la sexualidad. Sin embargo, el hecho de que en la segunda mitad del siglo xx se la descriminalice, es cierto, pero para aparecer bajo la forma de un peligro universal, es un cambio considerable. Yo diría que ahí está el peligro. ${ }^{44}$
\end{abstract}

En el fondo de esta discusión, podemos observar cómo la homosexualidad, una vez despenalizada (aunque parcialmente) es convertida ahora en una enfermedad contagiosa, de la que hay que protegerse, mucho más que de la sexualidad heterosexual. Así, por ejemplo, König se burla de estas diferentes formas de pensar el peligro de la sexualidad en uno de sus cómics tempranos más polémicos, «Der liebe Onkel», ${ }^{45}$ publicado en Das sensationelle Comicbook (1981). En él, se trata un tema bastante controvertido de una forma sumamente irónica y políticamente incorrecta. Las viñetas presentan un claro caso de pedofilia heterosexual, con el que König interviene en los debates conservadores de la época que asociaban la pedofilia solo con la homosexualidad. El tío querido del título engaña a una niña - kleines Mädchen - para que le practique sexo oral a cambio de un chocolate. Pero dos policías lo están espiando. El lector debe imaginar que ha de ser atrapado y enjuiciado por pedofilia: «Da sind sie, Herr Wachtmeister! Mein Gott, das arme kleine Mädchen!» [«iAhí están, señor guardia! ¡Dios mío, esa pobre pequeña muchacha!»]. Pero lo que los horrorizaba era pensar que «Der liebe Onkel» no cumpliera con su promesa de darle un chocolate. Así es que cuando esto sucede se quedan tranquilos: «Na, so was! Ich hätte schwören können, dass er dem Kind die versprochene Schokolade nicht gibt...» [«iMirá qué cosa! Podría haber jurado que no le iba a dar el chocolate que le prometió»] / «Na sehen sie, Herr Schulze!» [«iMire usted señor Schulze!»] / «... aber es gibt wohl doch noch ehrenwerte und ansträndige Menschen...» [«... pero todavía hay gente honorable y esforzada...»] / «Na, dann kann ich ja ruhig wieder gehen...» [«Bien, entonces me puedo volver tranquilamente...»].

\title{
Homosexualidad y terror
}

En Ralf König también encontramos una posible referencia al peligro que representa la homosexualidad todavía en los ochenta. En «Schwul-Comix live» ${ }^{46}$ tenemos, nuevamente, a

${ }_{43}$ Foucault, M. «La ley del pudor», en Sexualidad y politica. Escritos y entrevistas 1978-1984. Buenos Aires, El cuenco de plata, 2016, pp. 56-57.

${ }^{44}$ Ibid., p. 63.

45 König, R. Op. cit., p. 154.

${ }^{46}$ Ibid., pp. 30-31. 
un presentador de televisión, pero en este caso a uno que realiza críticas cinematográficas y muestra el adelanto de una nueva película de terror cuyo nombre es «Drei mörder-Schwanze» [«Tres penes asesinos»]. ${ }^{47}$ En la escena vemos a una pareja heterosexual cenando en un restaurante y expresándose su amor, pero él se da cuenta de que no le quedan cigarrillos y decide salir a comprar, en el camino piensa en lo orgulloso que está porque va a llevársela a la cama, pero es atacado por los drei mörder-Schwanze. Así como se personificaban las botellas de licor en «Old Heinz Comix» para dar cuenta de cómo biopolíticamente una vida gay es importante si se adapta a ciertos estándares de belleza y juventud, aquí se simboliza el terror y peligro que implica la homosexualidad a partir de la personificación de los tres penes asesinos. En su ataque de película de terror, los penes no solo lo golpean sino que se le meten en la boca y en el ano. De esta forma también se remite a cierta retórica del porno gay y de la representación del sexo grupal que hace más evidente la homofobia del supuesto filme que imagina König [FIG. 6]. Como afirma Gabriel Giorgi:

la solidaridad retórica entre homosexualidad e imaginación del exterminio no sorprende: la homosexualidad ha sido tradicionalmente asociada con la extinción de linajes, con el final de las familias y las progenies, la crisis del orden reproductivo, tanto biológico como cultural [...]. Enfermedades diversas y letales, desde la sífilis al sida, se asocian a la homosexualidad como un azote merecido en los espectáculos que los medios masivos montan en torno a ella. Sucesivas diagnosis culturales sobre sus perturbaciones psicológicas han hecho de los homosexuales una raza propicia de serial killers en ficciones literarias y cinematográficas. ${ }^{48}$

Asimismo, no solo se hace alusión a la homosexualidad, sino también a la promiscuidad asociada a esta. La homosexualidad está permitida siempre que se vaya acercando a la heterosexualidad, es decir, siempre que se rija por una homonorma.

Mediante el recurso de la película de terror, aparece la homosexualidad como un peligro que puede atacar en cualquier parte, pero más precisamente en ciertos sectores. Luego de la escena el conductor del programa presenta al director y guionista de la película, Karl Corruptus, que comenta que trabajó con un equipo de producción compuesto principalmente por Hugo Homokass y Marianne Tuntenkill y que la banda de sonido es de Anita Bryant. Es muy importante el uso irónico de los nombres, ya que todos remiten a la homofobia implícita en el filme: no solo el realizador se llama Corruptus, sino también el equipo de producción está compuesto por el odio a los homosexuales (Homohass) y el asesinato de locas o maricas (Tuntenkill). A su vez, Anita Bryant, la encargada de la banda de sonido en la ficción de König, es un personaje histórico. Se trata de una cantante estadounidense de éxito en los años sesenta, que en los setenta se vuelve la cara visible de la campaña homofóbica «Save our Children», contra la posibilidad de acceso de homosexuales a puestos de trabajo estatales. E1 presentador le pregunta por el reproche de que la película es muy homosexual, y Corruptus

${ }^{47}$ Cabe destacar aquí que la palabra alemana Schwanz tiene una connotación vulgar, por lo cual, más que por «pene», podría ser traducida por «pija» en español rioplatense o «polla» en español peninsular.

${ }^{48}$ Giongi, G. Sueños de exterminio: homosexualidad y representación en la literatura argentina contemporánea. Rosario, Beatriz Viterbo Editora, 2004, pp. 16-17. 
contesta: «Quatsch! Die Schwulen gehen ja selbst in den Film und einige finden ihn sogar gut. Die sind doch froh, wenn überhaupt mal was über sie in den kinosläuft» [ $i$ Tonterías! Los gays han ido al cine a verla y algunos la consideran una buena película. Están bastante satisfechos cuando se habla de ellos en el cine»]. En realidad, como comenta el presentador, los homosexuales han hecho protestas contra la película considerándola homofóbica, pero el director responde que el canciller federal (Bundeskanzler) consideró que era valiosa (wertvoIl) y que la juventud debería verla y, por otro lado, que ningún apicultor protestó con la película catástrofe «Die Bienen» [The Deadly Bees (Freddie Francis, 1966)]. En este sentido, la homosexualidad se configura como una enfermedad que contagia.
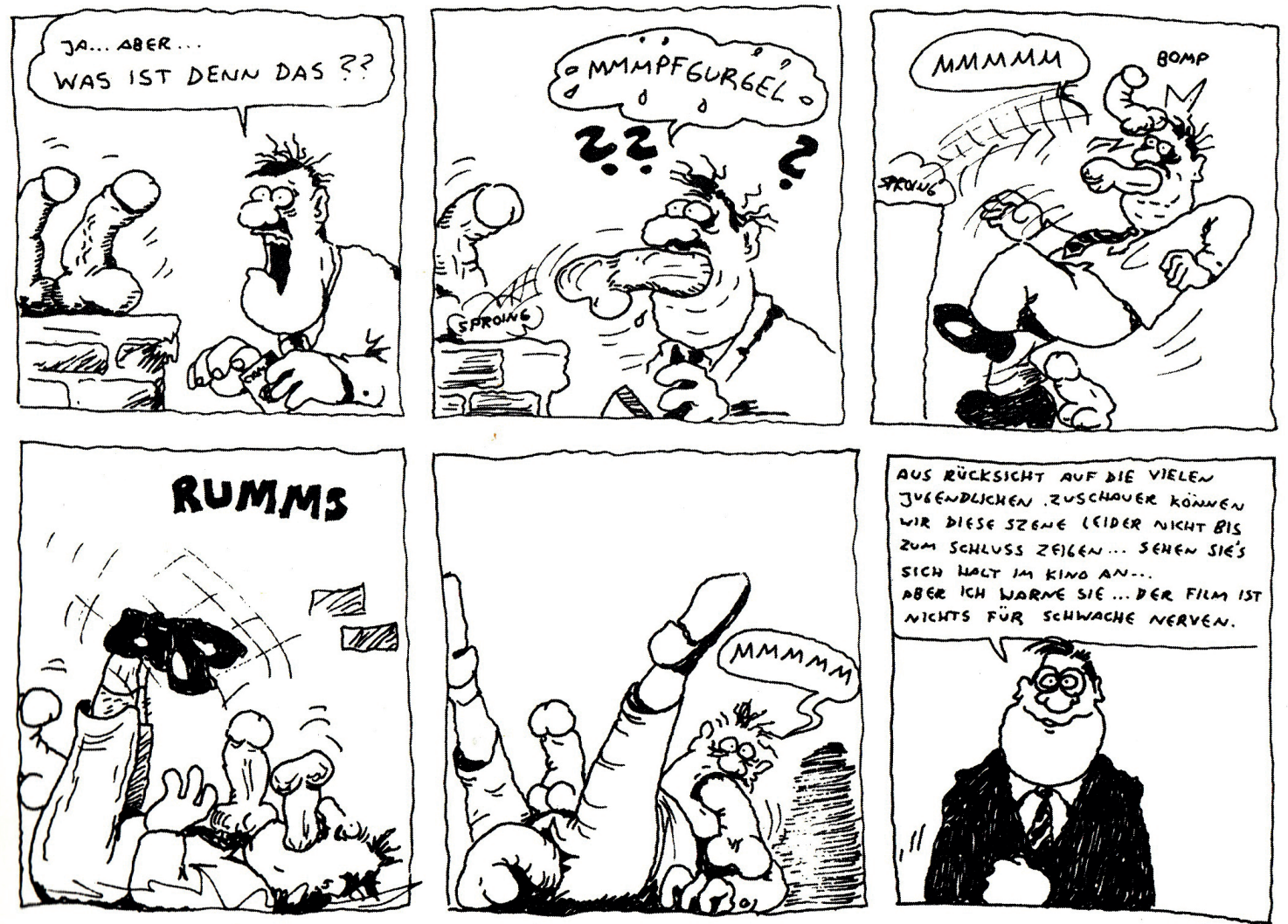

FIG. 6.KöNIG, R. «Schwul-Comix live», en Derjunge König. 1. Die frühen Comix (1980-1984) [Schwulcomix 1 (1980)]. Hamburg: Männerschwarm Verlag, 2014, p. 31 (detalle).

Las referencias al cine en König son un tema recurrente que va a reaparecer luego, en los inicios de la crisis del VIH-SIDA, en el ciclo «Kondom des Grauens» (1987/1990). ${ }^{49}$ A su

${ }^{49}$ Compuesto por las novelas gráficas Kondom des Grauens (1987) y su segunda parte Bis auf die Knochen (1990). Como comenta Malone sobre el mensaje de desconocimiento sobre la enfermedad, «the monster effectively symbolizes the anxiety caused by AIDS and the correspondingly intensified homophobia». 
vez, el cine de terror — como antes el género gótico—, tal como afirma Jack Halberstam, constituye una tecnología que produce subjetividades desviadas en oposición a las normales. ${ }^{50} \mathrm{El}$ horror, según Halberstam, se engendra a partir de la producción de una clase particular de cuerpos, los monstruosos: «Gothic fiction of the nineteenth century specifically used the body of the monster to produce race, class, gender, and sexuality within narratives about the relation between subjectivities and certain bodies». ${ }^{51}$ También Benshoff considera que se trata de un elemento más de lo que Foucault llama el dispositivo de la sexualidad, según el cual esta ya no es reprimida por la sociedad sino que resulta regulada por una serie de discursos como el legal, el médico, el religioso y el de los medios de comunicación, en el cual se incluye al cine como uno de sus más poderosos dispositivos. ${ }^{52}$ En el monstruo y en la ficción gótica que los crea —así como en el cine de terror-, Halberstam reconoce:

narrative technologies that produce the perfect figure for negative identity. Monsters have to be everything the human is not and, in producing the negative of human, these novels make way for the invention of human as white, male, middle class, and heterosexual. ${ }^{53}$

En este sentido, la tesis de Halberstam es que el monstruo total de la novela gótica, aquel que representaba en un mismo cuerpo raza, clase, género y sexualidad, ya no existe en el cine de terror. En este, la monstruosidad comienza a remitir solo a lo sexual: «The monster always represents the disruption of categories, the destruction of boundaries, and the presence of impurities and so we need monsters and we need to recognize and celebrate our own monstrosities». ${ }^{54} \mathrm{El}$ VIH-SIDA, en este sentido, no hace más que cristalizar los sentidos de la sexualidad disidente y promiscua relacionada con la enfermedad que ya estaban circulando:

El virus del sida, como si se tratara de una cristalización biopolítica tardía de algunas intenciones eugenésicas que Occidente había puesto a prueba a través del experimento nazi, cambia el medioambiente y las condiciones generales de inmunidad en el que se inventan nuevas estrategias de supervivencia y se llevan a cabo otras micropolíticas revolucionarias. ${ }^{55}$

Malone, P. «From Blockbuster to Flop? The apparent failure (or possible transcendence) of Ralf König's Queer Comics Aesthetic in Maybe... maybe not and Killer Condom», en Gordon, I., Iancovich, M. y McAllister, M. (eds.). Films and comic books, Jackson, University Press of Mississippi, 2007, p. 237. Asimismo, se trata de «una ficcionalización de las reacciones del colectivo gay (que emerge en la liberación sexual de los setenta) a la imposición del preservativo o condón como un mecanismo disciplinador del sistema». SAxE, F. (2014). Op. cit., p. 160.

${ }^{50}$ Halberstam, J. Skin Shows. Gothic Horror and the Technology of Monster. Durham and London, Duke University Press, 1995, p. 2.

51 Ibid., p. 6.

52 Benshoff, H. Monsters in the closet. Homosexuality and the horror film. Manchester y New York, Manchester University Press, 1997 , p. 9.

53 Halberstam, J. Op. cit., p. 22.

${ }^{54}$ Ibid., p. 27.

55 Preciado, B. P. Op. cit., p. 163. 
De esta forma, se puede pensar que los drei mörder-Schwanze del cómic de König condensan la monstruosidad de la homosexualidad y los peligros de su cercanía antes, incluso, del uso biopolítico del VIH-SIDA para condenar las prácticas promiscuas y liberadoras de las sexualidades disidentes.

\section{A modo de conclusión}

Me interesa pensar, en este sentido, cómo a comienzos de la década del ochenta, cuando la homosexualidad - ya no penada por la ley- comienza a ser supuestamente aceptada, se ponen en marcha nuevos regímenes de opresión y de exclusión que tienen que ver con la producción de lo humano, como puede ser, por ejemplo, su prohibición hasta la edad de dieciocho años o más; en tanto las relaciones heterosexuales, en cambio, seguían siendo legales para personas mayores de catorce años. Gayle Rubin considera que en la aceptación de ciertas vidas humanas e identidades hay una jerarquía de valores:

Las sociedades occidentales modernas evalúan los actos sexuales según un sistema jerárquico de valor sexual. En la cima de la pirámide erótica están solamente los heterosexuales reproductores casados. Justo debajo están los heterosexuales monógamos no casados y agrupados en parejas, seguidos de la mayor parte de los demás heterosexuales. El sexo solitario flota ambiguamente. El poderoso estigma que pesaba sobre la masturbación en el siglo xix aún permanece en formas modificadas más débiles, tales como la idea de que la masturbación es una especie de sustituto inferior de los encuentros en pareja. Las parejas estables de lesbianas y gays están en el borde de la respetabilidad, pero los homosexuales y lesbianas promiscuos revolotean justo por encima de los grupos situados en el fondo mismo de la pirámide. Las castas sexuales más despreciadas incluyen normalmente a los transexuales, travestís, fetichistas, sadomasoquistas, trabajadores del sexo, tales como los prostitutos, las prostitutas y quienes trabajan como modelos en la pornografía y la más baja de todas, aquellos cuyo erotismo transgrede las fronteras generacionales. ${ }^{56}$

En este sentido, siempre habrá un exterior que permita definir el adentro de lo humano, de lo normal y de lo aceptable: la monogamia, la familia, la respetabilidad, la discreción, van a ser requisitos para esa aceptación de las vidas homosexuales. La promiscuidad, la visibilidad o las prácticas disidentes como el BDSM se tensionan así con la posibilidad de aceptación social, que siempre implica una pérdida. En este sentido, la liberación disidente de los años setenta generó, también y paradójicamente, una pérdida de libertad, como harán notar una década después los estudios queer y su crítica a la normalización de lo gay-lésbico. Pero esto ya se estaba gestando en la década de los setenta y se podía observar más claramente en el año bisagra entre la década de la liberación y la década de la emergencia de lo queer: 1980.

A modo de conclusión, quiero detenerme en una última viñeta, la que acompaña al índice en la edición de 1980 de Schrulcomix 1 [FIG. 7]. En ella se lee: "Schwule sind Schweine, daran wird sich nichts ändern, sie werden bestenfalls geduldete Schweine”. Kurt Klein, Isenbrück in einer Lieserbrief an den "Stern" zum Schwulenartikel» ["Los putos son cer-

${ }_{56}$ Rubin, G. «Reflexionando sobre el sexo: notas para una teoría radical de la sexualidad», en VAnce, C. (ed.). Placer y peligro: explorando la sexualidad femenina. Madrid, Revolución, 1989, p. 136. 
dos, en eso no son otra cosa, en el mejor de los casos se convertirán en cerdos permitidos". Kurt Klein, Isenbrück en una carta de lector a "Der Stern" sobre un artículo sobre homosexualidad»]. En el cómic, vemos a un matrimonio que está sentado en un banco de plaza junto a un cerdo vestido como una persona. El cerdo solo gruñe - «Grunz»—, en tanto el matrimonio discute sobre la situación. Martha quiere irse a otro lugar porque le parece desagradable estar sentada junto a un cerdo — «Komm, Hans, lass uns woanders hinsetzen... mir wird übel...») - , pero Hans contesta: «Aber, Martha! Wie kann man nur so empfindlich sein. Man muss doch Verständnis für diese Schweine haben...» [Pero, Martha, cómo se puede ser tan sensible. Hay que tener comprensión con este cerdo]. ${ }^{57}$

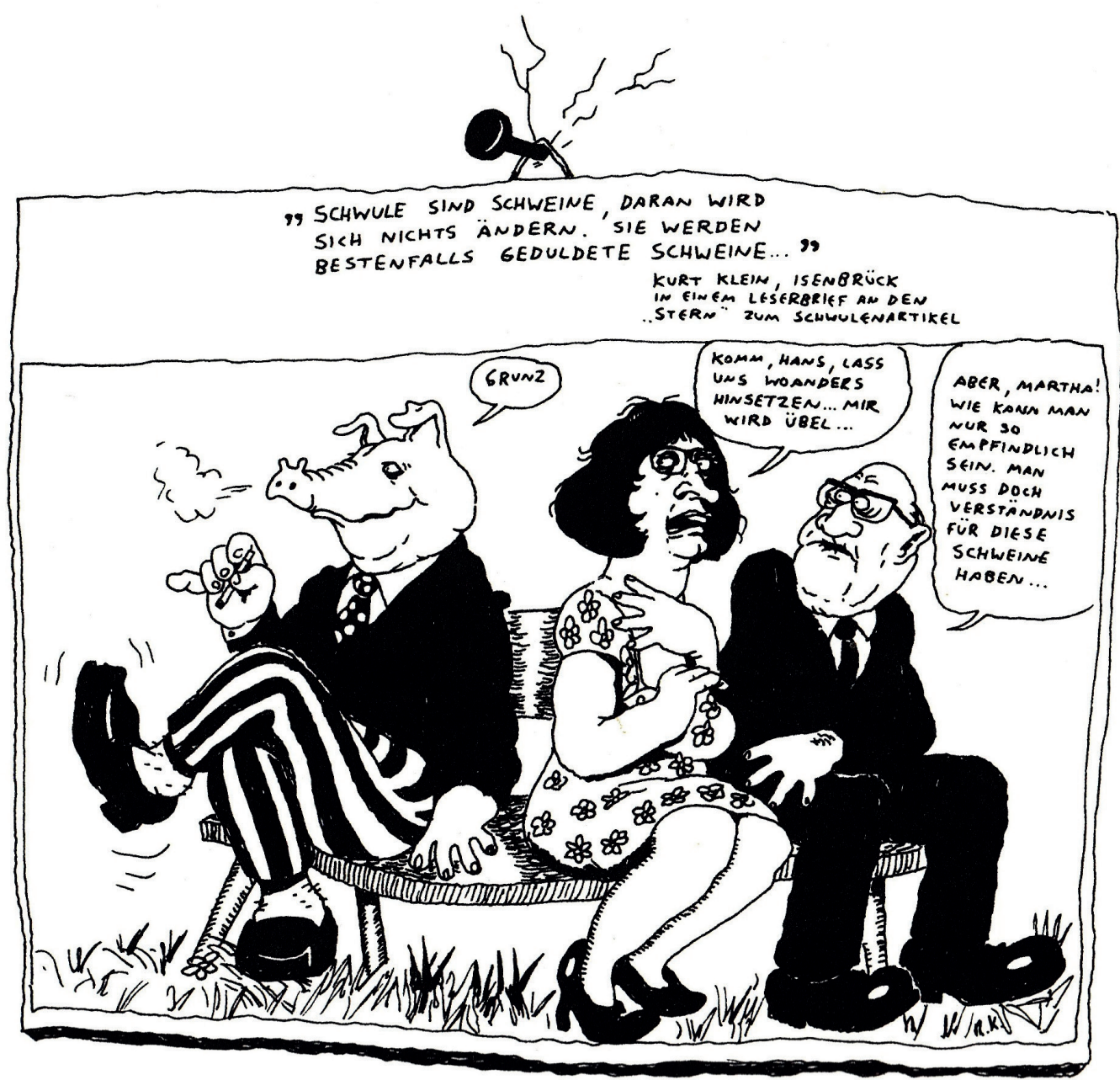

FIG. 7. KöNIG, R. Schwulcomix 1 (1980), en Der junge König. 1. Die frühen Comix (1980-1984). Hamburg, Männerschwarm Verlag, 2014, p. 16 (detalle).

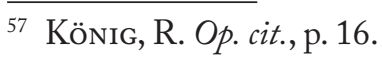


La imaginación humorística de König recrea una metáfora propia del idioma alemán para rebajar e insultar al tipo de personas que se consideran inferiores. En este caso los Schwul son Schweine, cerdos. Como comenta Giorgi:

\begin{abstract}
el animal en la cultura se constituye en un artefacto, un punto o zona de cruce de lenguajes, imágenes y sentidos, desde donde se movilizan los marcos de significación que hacen inteligible la vida como «humana» [...]. La vida animal conjuga modos de hacer visibles cuerpos y relaciones entre cuerpos; desafía presupuestos sobre la especificidad y la esencia de lo humano, y desbarata su forma misma a partir de una inestabilidad figurativa que problematiza la definición de lo humano como evidencia y como on tología. ${ }^{58}$
\end{abstract}

La animalidad humorística de König ${ }^{59}$ parece indicar, justamente, que sigue habiendo vidas a desproteger, vidas a abandonar, que no importan y cuyas muertes tampoco pueden ser lloradas. Se trata de lo que Agamben denomina como «vida desnuda», ${ }^{60}$ que se encarna en la figura del animal, del cerdo, como forma de vida no humana o, como muestra el recurso de la antropomorfización del cerdo en el cómic de König, vidas no del todo humanas. De esta forma, también produce una inversión subversiva del insulto, un gesto queer que resignifica la animalidad. En este sentido puede hacerse una lectura del devenir animal ${ }^{61}$ del Schwul como forma de fuga a la axiomática, no solo de la heterosexualidad como régimen político, sino también de la normalidad gay u homonormatividad, las condiciones de vidas homosexuales vivibles para lograr la hipócrita aceptación social.

${ }^{58}$ Giorgi, G. Formas comunes: animalidad, cultura, biopolítica. Buenos Aires, Eterna Cadencia Editora, 2014, p. 15.

59 Este recurso en la historieta también es usado por la famosa Maus: A Survivor's Tale de Art Spiegelman, que también comienza a publicarse de forma seriada desde 1980. Allí se representan a los judíos como ratones, a los alemanes como gatos y a los polacos como cerdos. En 1992 Spiegelman gana un Premio Pulitzer por esta obra.

60 Agamben, G. Homo Sacer I. Valencia, Pre-textos, 1998.

${ }^{61}$ Deleuze, G. y Guattari, F. Mil mesetas: capitalismo y esquizofrenia. Valencia, Pre-textos, 1988. 


\section{Bibliografía}

Agamben, G. Homo Sacer I. Valencia, Pre-textos, 1998.

Benshoff, H. Monsters in the closet. Homosexuality and the horror film. Manchester y New York, Manchester University Press, 1997.

Córdoba García, D. «Teoría queer: reflexiones sobre sexo, sexualidad e identidad. Hacia una politización de la sexualidad», en Córdoba García, D. Sáez, J. y Vidarte, F. J. (eds.). Teoria queer: politicas bolleras, maricas, trans, mestizas. Barcelona/Madrid, Egales, 2005, pp. 21-66.

Deleuze, G. y Guattari, F. Mil mesetas: capitalismo y esquizofrenia. Valencia, Pre-textos, 1988.

Devlin, P. The enforcement of morals. London, Oxford University Press, 1965.

Dobler, J. «Schwule Lesben», en Pretzel, A. y Weiss, V. (eds.). Rosa Radikale. Die Schwulenberwegung der 1970er Jahre. Hamburg, Männerschwarm Verlag, 2012, pp. 113123.

Duggan, L. The twilight of equality? Neoliberalism, cultural politics, and the attack on democracy. Boston, Beacon Press, 2003.

Foucault, M. «La ley del pudor», en Sexualidad y politica. Escritos y entrevistas 19781984. Buenos Aires, El cuenco de plata, 2016, pp. 49-69.

—Historia de la sexualidad. 1. La voluntad de saber. Madrid, Siglo xxi, 2007.

Giorgi, G. Formas comunes: animalidad, cultura, biopolitica. Buenos Aires, Eterna Cadencia Editora, 2014.

- Sueños de exterminio: homosexualidad y representación en la literatura argentina contemporánea. Rosario, Beatriz Viterbo Editora, 2004.

Halberstam, J. Skin Shows. Gothic Horror and the Technology of Monster. Durham and London, Duke University Press, 1995.

Haunss, S. «Von der sexuellen Befreiung zur Normalität. Das Ende der Zweiten deutschen Schwulenbewegung», en Pretzel, A. y Weiss, V. (eds.). Rosa Radikale. Die Schwulenberwegung der 1970er Jahre. Hamburg, Männerschwarm Verlag, 2012, pp. 199-212.

Holy, M. «Jenseits von Stonewall - Rückblicke auf die Schwulenbewegung in der BRD 1969-1980», en Pretzel, A. y Weiss, V. (eds.). Rosa Radikale. Die Schrulenberwegung der 1970er Jahre. Hamburg, Männerschwarm Verlag, 2012, pp. 39-79. 
Jagose, A. Queer theory: an introduction. New York, New York University Press, 1996.

KöNig, R. Derjunge König. 1. Diefrühen Comix (1980-1984). Hamburg, Männerschwarm Verlag, 2014.

Malone, P. «From Blockbuster to Flop? The apparent failure (or possible transcendence) of Ralf König's Queer Comics Aesthetic in Maybe... maybe not and Killer Condom», en Gordon, I., Iancovich, M. y McAllister, M. (eds.). Films and comic books, Jackson, University Press of Mississippi, 2007, pp. 228-245.

Mira, A. Miradas insumisas. Gays y lesbianas en el cine. Madrid, Egales, 2008.

Preciado, P. B. «Terror anal: apuntes sobre los primeros días de la revolución sexual». Hoceuenghem, G. y Preciado. B. P. (eds.). El deseo homosexual (con Terror anal). Barcelona, Melusina, 2009.

Rubin, G. «Reflexionando sobre el sexo: notas para una teoría radical de la sexualidad», en VANCE, C. (ed.). Placer y peligro: explorando la sexualidad femenina. Madrid, Revolución, 1989, pp. 113-190

Rubino, A. Sexualidades disidentes en la literatura y el cine de habla alemana (1969-1980) [Tesis Doctoral]. FaHCE-UNLP, 2017. Disponible en http://www.memoria.fahce.unlp. edu.ar/tesis/te.1406/te.1406.pdf

SÁEz, J. «El contexto sociopolítico de surgimiento de la teoría queer. De la crisis del sida a Foucault», en Córdoba García, D. Sáez, J. y Vidarte, F.J. (eds.). Teoría queer:politicas bolleras, maricas, trans, mestizas. Barcelona/Madrid, Egales, 2005, pp. 67-76.

SÁEz, J. Teoría queer y psicoanálisis. Madrid, Síntesis, 2004.

Salmen, A. y Eckert, A. «Die neue Schwulenbewegung in der Bundesrepublik Deutschland zwischen 1971 und 1987. Verlauf und Themen», en Forschungsjournal Neue Soziale Berwegungen n. 2 (1988), pp. 25-32.

SAXE, F. Representación transnacional de las sexualidades disidentes en textos culturales alemanes recientes (1987-2012) [Tesis Doctoral]. FaHCE-UNLP, 2014. Disponible en http:// www.memoria.fahce.unlp.edu.ar/tesis/te.992/te.992.pdf

SAXE, F. «Representación cultural de la disidencia sexual en el cómic: los "hombres deseados" de Ralf König en Der berwegte Mann», en CuCo, Cuadernos de cómic n. 10 (2018), pp. 8-27. Disponible en http://cuadernosdecomic.com/docs/revista10/Representacion cultural de la disidencia sexual.pdf

Warner, M. «Introduction», en Warner M. (ed.). Fear of a queer planet: queer politics and social theory. Minneapolis, University of Minnesota Press, 1993, pp. VII-XXXI. 